\title{
On the Translator's Responsibilities
}

\author{
Wang Ling, Zhang Kailing \\ Department of Foreign languages, School of Humanities, Tianjin University of Finance and Economics, Tianjin, China
}

Email address:

329903308@qq.com (Wang Ling), 799192249@qq.com (Zhang Kailing)

\section{To cite this article:}

Wang Ling, Zhang Kailing. On the Translator's Responsibilities. International Journal of Language and Linguistics. Vol. 3, No. 6, 2015, pp. 427-435. doi: 10.11648/j.ij11.20150306.26

\begin{abstract}
With the development of the translation theories, the focus of the translation criticism has also changed. The subjectivity or centeredness of the translator has been a hot topic in China, and the author of this paper considers that it is time to discuss the translator's responsibilities. This paper will study the responsibilities a translator should bear in detail by analyzing two Chinese versions of a short story written by William Somerset Maugham.
\end{abstract}

Keywords: Translator, Responsibility, Translation, The Luncheon

\section{Introduction}

Before the 1990s, the ideas of translation theories proposed by the Western linguistic group occupied a leading position among other translation theories in China. What that group concentrated on shifted from seeking the intentions of authors as the translation criteria to the definition of translation by J.C. Catford. He said "translation is an operation performed on languages: a process of substituting a text in one language for a text in another" (J.C. Catford, 1965). Thus he emphasized the language, the language text and substitution rather than authors' intentions. Later on, J.C. Catford's ideas were replaced by dynamic equivalence put forward by Eugene A. Nida, whose theories had a great influence on scholars at that time. During this process, we can easily see that Chinese translators and translation critics all put their focus and attention on the source language text (SLT). While dynamic equivalence or functional equivalence was associated with reception theory and readers' responses, it still considered the original as a most important standard which could be used to evaluate the target language text (TLT). Chinese scholars and translators supporting these ideas hold that the comprehension and language aptitude will be required if translators want to have a good understanding of the original and provide a better version. Many scholars during that period were just concerned about languages. Some even tried to compare the translated text with the source text in unfavorable ways. For example, they studied the versions translated by the renowned translators in order to find the smallest "fault", and were inclined to ignore the most splendid parts. "Cultural Turn" appeared in the 1990s and thus changed translation to a great extent. Translators and scholars began to get rid of the research paradigm raised by the linguistic group. Social and cultural contexts were given more concerns. Many factors apart from language were taken into account. Before long, the information of Manipulation School was introduced into China. Lefevere, as a member of Manipulation School, proposed the theory of rewriting that has enjoyed popular support in China. The three factors, including ideology, poetics and patronage, have aroused concerns of Chinese scholars since then. Following the change, the translator's status has also been boosted. It was firmly believed that the author was a host while the translator a servant in the first place, but gradually the translator's subjectivity was presented. According to a Chinese scholar called Tan Weiguo, "the subjectivity of the translator is reflected in his constant decision-making process, which includes two aspects: one is that the translator actuates his knowledge to correctly comprehend the SLT and successfully produce the TLT, which means that during the whole process the translator constantly makes proper choices based on his background knowledge; the other is that the translator carefully considers and conscientiously allows himself to be restricted by some elements related to translation, such as the SLT, the author of the SLT, the TLT readers, the idiomatic usage of the TL, etc" (Tan Weiguo, 2011: 37). Later on, another concept - translator centeredness - was put forward. The idea that the translator is in the central position during the translation is accepted by many Chinese scholars. Because the rights and status of translators are always mentioned in many journals, especially authoritative journals, it is, from my point of view, quite necessary to speak of the responsibilities accompanying the 
rights. The more rights the translator enjoys, the more responsibilities he should take. Otherwise, he may treat his job unmindfully and carelessly; he may forget his initial mission, which is to translate works from other cultures and promote the cultural communication. Many domestic scholars avoid or have no interest in talking about responsibilities while some just refer to them in a superficial way. Therefore, the paper will endeavor to study them through summarizing the relevant researches and analyzing a short story in detail.

\section{The Translator's Responsibilities}

\subsection{Some Relevant Studies Made in China}

Some researches and studies on the translator's responsibilities have been published in some Chinese journals, such as Chinese Translators Journal, and some other translation books. For example, Chen Zhijie and Yi Songming hold the viewpoint that reasonable responsibilities the translator shoulder should consist of three parts, that is, bottom-line responsibility, realistic responsibility, as well as future responsibility. According to their elaboration, bottom-line responsibility means the translator cannot do harm to every party involved in communication. In addition, he is forbidden to set up barriers and cause inconvenience for the communication. What the realistic responsibility expresses is that the translator has to satisfy the specific requirements of every party concerned. These parties include sponsors, clients, readers, the culture of the target language, the translator himself or herself, and so on. Future responsibility is a more abstract concept which means that the translator needs to pursue his or her own spiritual value when he or she begins to carry out translation (Chen Zhijie, Yi Songming, 2011: 77). Another two scholars need to be mentioned, that is, Lv Jun and Hou Xiangqun. They give their own explanations of the translator's responsibilities in $A n$ Introduction to Translatology co-written by them. They argue that " the translator's responsibilities can be divided into three parts, including social responsibility, academic responsibility and moral responsibility "(Lv Jun, Hou Xiangqun, 2012: 172). Social responsibility indicates that the books the translator chooses to translate and the versions wrote by the translator should be inspirations for other individuals in the same society, and should benefit the social development. There are two famous translators called Yan Fu and Lin Shu,. They both lived in the semi-feudal and semi-colonial old China. In order to enlighten people of his era and push forward social reform, Yan Fu decided to translate Evolution and Ethics and Other Essays written by Thomas Henry Huxley, and the Chinese version is 《天演论》. In addition, Lin Shu finished 《黑奴 吁天录》, which is the Chinese version of Uncle Tom's Cabin written by an American author Harriet Beecher Stowe. It is universally admitted that these two books have a profound impact on China. Many revolutionists, scholars and ordinary people had enlightenment in the two versions. The second responsibility is academic responsibility, referring that the translator has to bear in mind that one of his missions is to spread knowledge and disseminate science. Knowledge and science are so important that the translator needs to cultivate a sense of responsibility during his translation process. As is known to all, some translated texts of low quality will hinder the exchange of knowledge and academic communication. The last is moral responsibility. It stresses that how to choose the source text and how to translate are directly related to the translator's morality or even intuitive knowledge. For example, some choose the pornographic books which could corrupt public moral and cannot be tolerated in Chinese society. Someone else chooses books he is really not competent for. Those books are far beyond the translator's control. Others treat their work casually and carelessly, and they may translate without further thinking or further research. These translators pretend to know what they really do not; they refuse to have a deep understanding of the original, such as the background, the author and the genre and style of the original, and so forth. They just start to translate at the first sight. As a matter of fact, these behaviors mentioned above are irresponsible and the corresponding versions are unreliable.

These Chinese scholars introduce to us their understanding about the translator's responsibilities. From their explanations, we realize how important the responsibilities are and how important whether the translator holds responsibilities or not. These will influence the production of a wonderful translated text, and whether the version can enjoy a broad readership. Furthermore, whether the translator satisfactorily performs his responsibility can exert an influence on the dissemination of knowledge and ideas, as well as make a contribution to the society of the target language. However, they explain the responsibilities from the macroscopic aspect. How the translator practices can be considered to be qualified and responsible?

\subsection{Some Relevant Studies Made in Western Countries}

In 2001, there was a special column called "The return to ethics" in The Translator. Ethics, according to the third edition of Oxford Intermediate Learner's English-Chinese Dictionary, have two kinds of meanings, one of which is the study of what is right and wrong in human behavior; the other is the beliefs about what is morally correct or acceptable. Then, translation ethics denote the beliefs about what is morally correct or acceptable during the whole process of translating (including pre-translating and post-translating). Translating is an activity affected by textual factors, such as language and style, and extra-textual factors, such as sponsor, client and social culture. Translation does not take place in vacuum because the translator will infuse his morals or values into meaning construction. Thus the translation ethics in the possession of the translator will implicitly affect that process. Besides, Andrew Chesterman suggested in Proposal for a Hieronymic Oath that translation ethics should be classified into four sorts and added the fifth sort later. The five kinds of translation ethics are comprised of ethics of representation, ethics of service, ethics of communication, and norm-based ethics as well as ethics of commitment (Chesterman. A, 2001). In light of Chesterman's classification, Sun Zhili, a Chinese scholar, 
divides the translator's responsibilities into five parts as follows.

- Firstly, the translator should represent the source language text.

- Secondly, the translator should fulfill the requirements made by clients.

- Thirdly, the translation should be in accordance with the social and cultural norms of the target language.

- Fourthly, the translator should satisfy the needs of the target readers.

- Fifthly, the translator should adhere to professional ethics. (Sun Zhili, 2007: 7-10)

Compared with the scholars mentioned above, Sun Zhili's division is much more clear and specific. As far as I am concerned, what Andrew Chesterman and Sun Zhili stress is quite different from Lv Jun, Hou Xiangqun and Chen Zhijie. In fact, what they describe is another ethic - professional ethic and another responsibility-professional responsibility. However, all of the translator's responsibilities explained above can complement each other. Here we may raise a question as to why there are differences among the explanations of the translator's responsibilities in China and abroad. Actually, the condition and situation of translation in China are very different. Compared to the great number of people studying foreign languages, there are a few people choosing translation as a full-time job. China is short of the professional translators of high quality. And many wonderful versions enjoying great popularity are translated mainly by literary translators. What is worse, a lot of non-literary versions are easily ignored and forgotten. Therefore we can understand the reason why Lv Jun and Hou Xiangqun lay emphasis on academic responsibility. On the contrary, since there are many professional translators in western countries, they particularly stress professional responsibility. The different descriptions of the translator's responsibilities are the result of different social situation. The paper will observe whether translators perform their responsibilities and how they perform by analyzing two Chinese versions of a short story written by William Somerset Maugham, called The Luncheon. The analysis will be based on Lv Jun, Hou Xiangqun and Sun Zhili's ideas about the translator's responsibilities.

\section{Two Chinese Versions of The Luncheon and the Translator's Responsibilities}

\subsection{The Introduction to William Somerset Maugham and the Luncheon}

William Somerset Maugham, as one of the best known novelist, playwright in the $20^{\text {th }}$ century, produced many novels and short stories that are widely loved. Many of his works were best-sellers at that time. His novels, such as The Moon and Sixpence, The Razor's Edge and Of Human Bondage are very popular in China while his plays, travel notes, book reviews or even some of his short stories are often neglected by Chinese readers and scholars. Of course, most of
Maugham's short stories have been introduced into China, such as The force of Circumstances, Rain, Verger and The Luncheon. Many of his short novels are thought highly of by the Chinese scholars, and they believe these stories have shining features. Just as Chen Dun once wrote " many of his short stories have compact structure, special plot, colorful exotic atmosphere, and permanent artistic charm which make them treasures of short stories all over the world" (Chen Dun, 2007). In addition, some other Chinese people assert that Maugham follows three rules in his writing style: lucidity, simplicity and euphony. Actually, Maugham does embrace popularity among many Chinaman.

The Luncheon that this paper focus on is an interesting and humorous short story which has those wonderful features mentioned above. Maugham uses less than 1700 words to describe vividly a scene of a writer and a woman having dinner and a waiter serving them in a luxurious restaurant. In this short story, the most striking point is that the author uses many figures of speech and psychological words in a wise way so that these three characters' different personalities are displayed clearly. Therefore, whether the translator can translate these rhetorical devices correctly and precisely is a main standard to judge if the version is good or bad. In order to find out which translator really holds his responsibilities and how they perform their responsibilities respectively, the paper will compare two Chinese versions of The Luncheon, one of which was translated by Po Shi in English Language Learning in 2002, while the other was translated by Fu Weici who contributes a lot to the introduction of Maugham's works into China. Though there are thirteen kinds of rhetorical skills used in the short story, this paper will just pay attention to nine whose translations have sharp contrasts. We will discuss these contrasts step by step.

\subsection{The Comparison of the Translation of Different Rhetorical Skills in the Two Versions}

\subsubsection{Euphemism}

Euphemism refers to an indirect word or expression that you use instead of a more direct one when you are talking about something that is unpleasant or embarrassing, for example, sex, age and death.

Example 1: We're none of us getting any younger.

Po Shi: 我们都不年轻了.

Fu Weici: 我们也都老了.

Actually, these two versions have the same meaning. But Fu Weici uses the Chinese word “老” which represents old in his translation, and Po Shi expresses it in a more roundabout way. As we all know, women in the West view age as a privacy, so they often use euphemism when talking about it. However, Chinese people, especially the elderly, are very willing to acknowledge their age, which reflects the cultural difference. In my opinion, the writer uses the rhetorical skill here that demonstrates a part of the western culture, then we should show our respect to it. Hence Fu Weici's version is a little bit direct so that it is not helpful for the portrait of the woman having dinner with the protagonist, however, Po Shi does maintain the cultural element, so Po Shi's translation is 
much more acceptable. It arouses the target readers' attention to the special figure of speech and the social culture in western countries. It is very easy for us to neglect this rhetoric. When the translator begins to translate, he should be aware of differences between the two cultures. Rhetoric is also part of culture and can reflect culture to some degree, so the translator has to study the different figures of speech used in different cultures which will help him to deal with translation. We can see that one of the translator's responsibilities is to keep learning. In order to accomplish the representation of the original, he must keep studying the differences between two or more cultures.

\subsubsection{Rhetorical Question}

Rhetorical question is a question does not expect an answer because the answer is in the question.

Example 2: Did I remember?

Po Shi: 我还记不记得?

$\mathrm{Fu}$ Weici: 我怎么能不记得.

The rhetorical question used in the beginning of The Luncheon services as a connecting link between the preceding and the following, and between the first meeting and the second meeting of the protagonist with the woman 20 years before and 20 years later. This question implies that of course "I" still remembered, showing that the protagonist was still bothered with the luncheon and was not broad-minded. Short as it is, it plays an important role in the whole short story. By comparing the two translations of this figure of speech, we can find that $\mathrm{Fu}$ Weici's is in accordance with Maugham's intention and the context. Fu Weici's version is much useful to describe the protagonist while Po Shi's is just an common question which does not convey the writer's intention. Po Shi does not grasp the tone of the protagonist so he just translates it surfacely. In addition, if the full stop in Fu Weici's version is replaced by a question mark, it will be perfect. From my point of view, Fu's translation is rather better.

\subsubsection{Understatement}

Understatement is to say that something is smaller or less important than it really is. One of the obvious features this rhetorical skill has is that the adverbs, such as very, much, are often replaced by other downtoners, such as barely, a little, and so on. The understatement used in the story does not change the effect. On the contrary, it reinforces the effect.

Example 3: I was earning barely enough money to keep body and soul together.

Po Shi: 我赚的钱仅够糊口.

Fu Weici: 我的收入刚好够维持住我的灵魂和躯壳不分 家.

Honestly speaking, understatement used in the story does increase the charm of its narration, that is, through every statement or sentence that contains this figure of speech, we can observe each character's personality calmly and objectively. In this sentence, "barely enough" indicates that the protagonist, as a writer, was sorry underpaid. Maybe he just made both ends meet. Po Shi adopts the liberal translation strategy to cope with this rhetorical skill, however, this strategy does not display Maugham's humor at all because it just tells the readers the protagonist's financial condition in a simple and straightforward way. Nevertheless, Fu Weici chooses literal translation strategy to handle it. "Barely enough” is “刚好够”. “Body and soul” is “灵魂与躯壳”. Fu Weici notices Maugham's humor so his translation is humorous too. He does reveal the distinctive feature of the story fully. Here we may begin to understand that Fu Weici has a good command of Maugham's writing style. As a matter of fact, style is a part of meaning. It is a very important factor if the translator wants to represent the original and performs his responsibility.

Example 4: Would I give her a little luncheon at Foyot's afterwards?

Po Shi: 问我是否愿意请她在弗沃特餐厅吃一顿简单的 午餐?

$\mathrm{Fu}$ Weici: 问我是否愿意中午请她在福约特餐厅随便吃 点什么?

A little, as a downtoner, has appeared for many times in the short story and is used mainly to describe the woman's personality-greed and cunning. Then how to deal with the adverb will be better? We may note that this is an indirect speech. It is colloquial and informal. We have to pay attention to that point. Po Shi translates "a little" into “简单的” which means simple in Chinese. "A little luncheon" is an adjective plus a noun, so he uses an adjective plus a noun in Chinese instead. Actually, Po Shi is influenced by the original very much; he does not choose the most idiomatic Chinese to translate. While Fu Weici's version is the most idiomatic and colloquial Chinese which always occurs in Chinese people's daily life. Translation consists of understanding and expression. When the translator has a deep understanding of the source text, he should have the ability to translate what he understands. If the translation is awkward, it will not be considered to be a good translation. In addition, it will influence the author's image because many readers who do not acquire foreign languages always view the translated text as the original.

Example 5: Unless you had a little caviar. I never mind caviar.

Po Shi: 除非你这里有鱼子酱. 我不介意要点鱼子酱.

Fu Weici: 除非你们有鱼子酱. 吃点鱼子酱我倒不反对.

Both translators translate former sentence in the same way. A little caviar is “点鱼子酱”. “点”means a little bit in Chinese. The word "never" is also a hint of understatement. However, both translators just overlook it and do not show it in their Chinese versions. Because caviar is very expensive and precious, the woman was willing to have it all the time. Never is the representation of time, meaning from the past to the present. Therefore, I hold that it might be better if we add "— 向” to their translations, that is, “吃点鱼子酱我一向不反对” will be much suitable.

\subsubsection{Antithesis}

Antithesis means the opposite of something or a difference between two things.

Example 5: But when I walked out of the restaurant I had the whole month before me and not a penny in my pocket. 
Po Shi: 但是当我走出餐厅时,接下来还有整整一个月, 而我的口袋里一分钱也没有了.

$\mathrm{Fu}$ Weici: 但是我在走出饭馆时, 带着一张嘴和一个肚子, 但口袋里却一文不名.

As far as I am concerned, each of the two versions has its own merit and demerit. The right translation of " restaurant " is “餐厅”rather than “饭馆”. In Chinese, “餐厅”is much more great and wonderful than “饭馆”. “饭馆” is just a common place for people to have meals while “餐厅” is very luxurious and beautiful. According to the previous information, Foyot's is a restaurant at which the French senators eat. Then we can know it is not a common place where everyone can afford to eat, therefore, “餐厅” is the right translation. In addition, "the whole month" and "not a penny" is an antithesis, Po Shi's translation “整整一个月, 一分钱没有” seems correct at the first sight, but there is a logical mistake in The Luncheon. In the beginning of the short story, the protagonist thought to himself that "if I cut out coffee for the next two weeks I could manage well enough", so we know that there were just two weeks in the rest of the month. Then how can there be "the whole month before"? We could not tell it is Maugham's intention or just a careless mistake. But if the careful readers find the unreasonable point, they will not consider it as a wonderful story. The mistake will be unforgivable to some Chinese readers. It is obvious that $\mathrm{Fu}$ Weici found the illogical part, so his translation is “带着一张嘴和一个肚子” which means "I had a mouth and a belly". Actually, Maugham is Fu Weici' $s$ favorite writer, he believes that it is necessary to avoid the literal translation and make the story keep a good impression on the target readers. This paper holds that his choice is a manifestation of the translator's subjectivity. He chose to correct the error and gave up the translation of the rhetorical skill. But he did vividly describe the poor condition of the protagonist after the luncheon. Of course, correcting the errors of the original is not one of the translator's responsibilities. It is just concerned with how to make the source text well-received. But Sun Zhili has a different viewpoint, he thinks that the translator needs to convey the full sense of the original. However, as to those deficient texts, a hundred percent of representation is impossible. So he argues that the translator needs not translate the deficient contents faithfully, and it is the translator's responsibility to correct the errors and mistakes. In my opinion, correcting the inaccurate contents is not the translator's responsibility because it is a matter of choice. Correcting or not depends on the translator's decision which is influenced by the translator and the sponsor's intentions. Their purposes will be affected by the whole social and cultural atmosphere. There are so many factors influencing the translator's final choice. Therefore, we can say it is the translator's responsibility to represent the original faithfully, but we cannot say absolutely that correcting the deficient contents of the original is the translator's responsibility.

\subsubsection{Repetition}

Repetition means doing something again or something that you do or that happens again. Here this rhetorical skill means repeating the use of some words, some sentences or some paragraphs, which can highlight some intention or feeling of the writer or the protagonist. In The Luncheon, Maugham tries to portray that the woman who had lunch with the young author was very good at grasping the psychology of the protagonist. So she could get what she wanted step by step. Faced with the figure of speech, the two translators have their own ideas and deal with repetition in a very different way.

Example 6: I never eat more than one thing (for luncheon).

Po Shi: (1) 我只吃一样东西 (2) 我向来只吃一样东西 (3) 就只吃一样东西呢? (4)午餐时我向来只吃一点 (5) 午餐吃 的东西不要多于一种.

Fu Weici: (1) 我只吃一道菜 (2) 我中午只吃一道菜 (3) (学学我) 我只吃一道菜? (4)中饭我至多只吃一道菜 (5)中饭千万只吃一道菜.

Repetition has appeared for five times in the whole story. It is a shining feature of The Luncheon, which impresses the target readers deeply. The woman always emphasized that she just ate one thing for luncheon, but we know she was just a liar. During the lunch, she ate many expensive and luxurious things, consisting of salmon, caviar, champagne, asparagus, coffee and ice cream, as well as peach. Then every repetition of this sentence just makes the readers dislike or even disgust her. So it is very important to translate the rhetorical skill faithfully in order to create the same effect. Through the comparison of the two versions, we can find that Fu Weici insists on the repetition, so “一道菜” that means a course has repeated for five times. His translation is close to the original from form to meaning. When Chinese readers read the translated text, they will find the repetition easily. Actually, Fu Weici's translation has achieved what Nida called "dynamic equivalence". His dynamic equivalence is defined as a translation principle, according to which the translator seeks to translate the meaning of the original in such a way that the target language text wording will produce the same impact on the target text audience as the original wording does upon the source text audience (Tan Weiguo, 2011:10). On the contrary, Po Shi's translation is very different. It seems that he does not notice the use of repetition, so he does not translate the figure of speech satisfactorily, which just conceals the shining feature that the original possesses. From my point of view, the translator's first responsibility is to be a careful reader. You can find the wonderful points of the source text only if you are careful enough. Being careless will, on the one hand, does harm to the representation of the original, on the other hand, will not satisfy the target readers at all. It means he does not really become a bridge for the communication between the writer of the original and the readers of the target language.

\subsubsection{Irony}

Irony refers to a way of speaking that shows you are joking or that you mean the opposite of what you say. This figure of speech used in the short story expresses both the ironic and humorous tone. Therefore, the whole story makes readers feel interesting and relaxed rather than heavy or angry. Maugham employs this rhetorical skill to describe the personality of the woman and show the protagonist's attitude towards her. Irony 
also indicates the character of the protagonist, that is, he was narrow-minded. The two translators deal with the rhetoric in a little different way.

Example 7: But I've just had a snack.

Po Shi: 但我只吃了一点点.

Fu Weici: 而我只随便像吃点心一样地吃了点.

Example 8: Today she weighs twenty-one stone.

Po Shi: 今天她的体重肯定有21英石.

Fu Weici: 今天她体重三百磅.

When we compare the translations carefully, we can see that the word "snack" is translated by Fu Weici while Po Shi omits it. But this word is very important. The woman was so greedy and thus compared those luxurious foods as the snack. So the word is very useful to demonstrate what kind of person the woman was. Therefore it is quite necessary to maintain the word. In addition, the two translators choose different units of measurement. Po Shi chooses the literal translation strategy and maintains the "stone" in his version, while Fu Weici changes "stone" into "pound" which means "磅” in Chinese. Mr. Fu does some calculation when he meets the special unit of measurement in the original. No matter which unit of measurement they choose, we can find that they continue to use those often employed by the western people. Selecting "stone" or "pound" is very helpful to maintain the exotic tone in the translated text. However, many Chinese readers are not familiar with those units of measurement at all. When they read this sentence, they cannot get the humor at once. Therefore, these two translators maintain the exotic tone but let the humor slip away. We have to say it is the humor that makes the original interesting and impressive. Some people may suggest that we can add an annotation or footnote to explain “英石” or “磅”. But the humor still goes away when readers finish reading the annotation or footnote. Short stories are not like those informative texts. We do not read the short stories so as to learn units of measurement used in different countries. The most striking point in The Luncheon is humor. When the readers of the source language read this sentence, they will be very happy. However, when the readers of the target language read it, they will feel puzzled. Compared with exotic tone, humor is much more important. Thus, in order to keep the humor in the translated text, I assert that we can translate it by using the unit of weight prevailing in China. So I choose “公斤” which means kilograms in English. Then the translation will be “今天她体重 134 公斤”. Style is a part of meaning, but it is also something that is not easy to be kept when translated. But if we have a deep understanding of the original and bear in mind all the time that style is very significant. The translation can be much more closer to the source text. Sometimes we may encounter the dilemma, and we may have to make a choice, but we have to succeed in keeping the most important part. In The Luncheon, humor and irony are much more important. It is not easy for the translator to perform his responsibilities perfectly. Representation may sounds easy but it is not so easy as always supposed. It is concerned with many difficult choices which are based on the translator's analyses. In most of time, the translator has to decide which is more important and which must be kept. No matter what decisions he makes at last, he should give reasonable explanations.

\subsubsection{Parallelism}

Parallelism, as a figure of speech, means to strengthen the emotion or the feeling by putting together at least three phases or sentences that have similar structure, relevant meanings, and the same tone. The two translators handle the rhetorical skill differently.

Example 9: She ate the caviar and she ate the salmon. She talked gaily of art and literature and music.

Po Shi: 她吃着鱼子酱和鲑鱼,愉快地谈论着艺术, 文学, 音乐.

$\mathrm{Fu}$ Weici: 她吃掉鱼子酱.她吃掉鲑鱼.她谈笑风生地谈 论艺术,文学, 音乐.

Example 10: He assured me that they had some so large, so splendid, so tender, that it was a marvel.

Po Shi: 他向我保证他们绝对有那样巨大的,鲜嫩的, 美妙的芦笋,令人称羡.

Fu Weici: 他对我说他们有一些那么大, 那么好, 那么嫩 的龙须菜, 简直绝无仅有.

Through comparing the translators' versions, it is easily found that Po Shi's translation is too plain. He does not deliver the figure of speech to the target readers, and just describes a scene of having normal dinner. But Maugham does not endeavor to depict a usual and happy meeting of two good friends. Furthermore, Maugham uses parallelism to display that the woman just steeped herself in the abundant food and ignored the young author. Hence, Po Shi seems to neglect the figure of speech and fails to represent the original faithfully. His translation weakens the tone of the source text while $\mathrm{Fu}$ Weici succeeds in representing it and his version also employs Chinese parallelism. As for the second parallelism sentence, we notice that the word "so" has appeared for three times. We judge this sentence is a parallelism because of the repeated word. Therefore, it is quite important to translate the three "so" successfully. However, Po Shi only takes notice of the three adjectives modified by "so" and thus actually forgets the repeated word. Because Po Shi puts emphasis on those adjectives, he does not translate the sentence faithfully. The readers cannot guess that there is a parallel structure in the original when they read his translation. What is worse, he may understand what the word "marvel" means, but his Chinese translation is very bad. “令人称羡” means someone is jealous of something owned by the other person. In Chinese, it cannot be used to describe food. On the contrary, the three "so" become three“那么” in Fu Weici” s version. He insists on the parallel structure and strengthens the tone like the original does. His translation is much more impressive and faithful. For those readers who have a little command of English, they can feel the beauty of the original from Fu Weici's version. In order to represent the original in the target culture, the translator needs to be careful and should have the ability to keep the feeling or the tone of the writer. If the source text is beautiful and interesting, the translation cannot be plain and boring. The translator should improve his sensitivity to the beauty and his capability of appreciating the beauty. It is 
another responsibility which the translator has to shoulder if he wants to give a good version to the target readers.

\subsubsection{Metaphor}

Metaphor refers to a word or phrase that is used in an imaginative way to show that somebody or something has the same qualities as another thing. The use of metaphor is helpful to make the thing you are to describe vivid. Maugham employs this figure of speech to describe the peach in The Luncheon.

Exmaple 11: They had the blush of an innocent girl; they had the rich tone of an Italian landscape.

Po Shi: 那些桃子颜色象是纯洁少女脸上的粉红; 充满 着意大利风景的丰满色调.

Fu Weici: 红得好像纯洁的姑娘的脸蛋, 色调有如意大 利绚丽的风景画.

In fact, these two translators deal with the rhetorical skill in the same way. They both substitute the simile in Chinese for the metaphor in English. In Chinese, the feature of the metaphor is the occurrence of the Chinese words, for example, “是, 就是, 成了, 成为, 变成”, while the obvious feature of simile is the occurrence of other Chinese words, such as“像, 好像, 有如”. It is very essential to make a distinction between metaphor and simile, as well as to be familiar with how to use these two figures of speech and their characteristics in China and abroad. Thus we may draw a conclusion that these two translators are not adept at making a distinction because they are blind to the subtle. However, for another, by comparing the versions, Fu Weici's translation is much more acceptable and beautiful for the structure of his version is better than Po Shi' s. Po Shi seems to use the word-to-word translation method without any readjustment of the Chinese words. The writer succeeds in describing that the peach is so appetizing and attempting although he just uses some simple English words. But Po Shi fails to represent the intention of the writer. But Fu Weici does achieve the same effect as Maugham does. The target readers can feel the beauty of the peach. In addition, his translation conveys some exotic tone. Chinese readers seldom compare the color of peach as Italian landscape. Just as Lin Yutang once said "translation should not only be faithful, but also be 'beautiful"'. From my viewpoint, the beauty of translation consists of two kinds of meanings: one is that if the original is beautiful, the translation has to be beautiful rather than plain or even ugly; the other is that if the original is not beautiful, then the translation needs to be readable and comprehensible. Good translation should get rid of the sign of translating. Good translators should continue to improve their ability of expression. Sometimes, the reason why the translator fails to translate successfully is not because he does not understand the source text but because he does not good at expressing in the target language. We have said for many times that one has to be a poet first if he wants to translate poems of other poets wonderfully or even perfectly. It sounds very reasonable and tells us that it is very significant to promote the ability of expression.

\subsubsection{Simile}

Simile refers to a word or phrase that compares something to something else, using the words 'like' or 'as'. Thus, it is very easy to judge whether the sentence is a simile or not.

Example 12: A happy smile spread over his broad, priest-like face.

Po Shi: 开心的微笑在他宽大的, 牧师般的脸上绽开.

Fu Weici: 一个快乐的笑容掠过了侍者的神甫似的大脸.

These translators actually cope with the simile in the same way. But their understandings of the word "priest" are very different. In fact, Chinese people always feel puzzled because they are only acquainted with Christianity while knowing a little about Puritanism, Catholicism or the Orthodox Church of the East. According to the study of Maugham, we know that he lived in the $20^{\text {th }}$ century, at that time, the church of England is Anglican Church. In China, we always use “牧师” to represent a member of the Christian clergy in the Anglican Church, and “神甫” or “神父” as a Catholic. Therefore, we can see that Po Shi's version is right while Fu Weici's understanding is mistaken. The translator has to bear heavy responsibilities in most of time. In order not to let the writer of the original down, as well as to satisfy the target readers, he has to gain a lot of new knowledge. That is to say, he has to study the culture of the original prudently which covers both the secular and religious cultures that are not familiar to him. When confronted with some unfamiliar parts, the translator cannot take it for granted but has to do a careful investigation. It is a good quality that a translator should possess.

Po Shi is the first translator who translates The Luncheon. There is no doubt that his version arouses our attention to this short story. To some extent, he plays a positive role in the spread of Maugham's works in China. However, as the first version, it is not of high quality and cannot impress the Chinese readers deeply. Just from the translation of the figures of speech, we can find that Fu Weici's version is much better than his although $\mathrm{Fu}$ Weici also makes some mistakes. Of course, Maugham is one of Fu Weici's favorite writers. And he is a famous literary translator who focus on the study of Maugham. Actually, he has a deep and comprehensive understanding of Maugham compared with many Chinese people. He knows how to represent Maugham's humor and irony in Chinese. Hence, we can guess that the study on the writer of the original is very helpful for translation.

\subsection{The Translator's Responsibilities}

From the analysis mentioned above, we can have a shallow understanding of the translator's responsibilities. To some degree, what the paper analyses conforms with the scholars' opinions about the translator's responsibilities. However, I do not agree with them totally.

The Chinese scholar Sun Zhili said the fundamental responsibility that the translator should hold is to translate the source text faithfully if there are not any other factors that need considering (Sun Zhili, 2007: 7-10). And in order to translate the source text faithfully, he believed that one should correctly understand the original by trying to collect all the information related to the text and its writer. That is very reasonable. However, at the same time, he argued that the faithful translation was to convey the exact meaning of the 
original rather than the meaning that the translator perceives. It may sound true, but when you think further, you may find that it is really difficult to make a distinction. We cannot understand the writer totally even though we collect a lot of information about him; we cannot know clearly his state of psychology when he creates his works; we cannot communicate with the writer directly in most cases. Translation dose not take place in vacuum. The translator brings his own preconception into the understanding of the original. The preconception includes the translator's social and cultural backgrounds, educational level, previous experiences, his knowledge of the source text, and so forth. The translator uses his preconception to understand the spots of indeterminacy which are always the charm of the original. Translators have different preconceptions, so there are different versions provided for the target readers. In addition, Sun Zhili believed that the translator is responsible to correct the deficient contents in the deficient texts, while just as I mentioned above, that is absolutely not the case. It is the writer not the translator that has to be responsible for what he writes. No matter what decisions the translator makes, it is just a matter of choice based on many considerations. Therefore, correcting the deficient text is not the translator's responsibility at all.

Furthermore, the translated texts should be readable and understandable so that they can be acceptable. The translator has to translate in an idiomatic way and makes the information of another culture understood by the target readers. Then he has to keep raising his ability of expression. It is the translator's responsibility to persist in learning. There is another word "intersubjectivity" that we should pay attention to, that is, the translator should remember that he has to be responsible for the writer and the readers who will read his translation. He should play a role in the communication of two or more cultures; he should act as a bridge to link the people from different cultures; he should be very sensitive to the cultures' differences; he should be responsible for his job.

Though it is just a very short story, the two Chinese versions of The Luncheon really reflect many problems often taking place in the process of translation. These problems are concerned with translators' structure of knowledge, their attitude toward their work, their ability of expression, and so on. We need to take these issues seriously, because if we do not, the quality of translation will not be improved and finally the ignorance will be very harmful to the development of translation undertakings. The translation of The Luncheon also helps to spread knowledge, for example, the knowledge about different rhetorical devices used in different nations. Thus, to a great extent, we can conclude that $\mathrm{Fu}$ Weici does hold the academic responsibility.

\section{Conclusion}

We attach great importance to discuss the translator's responsibilities by analyzing the short story written by Maugham so as to highlight the importance of such traits that a good translator should have. We are intended to improve the translator's sense of responsibility before or when they translate. Lv Jun and Hou Xiangqun divided the translator's responsibility into social, academic, and moral responsibility. Of course, the division can remind the translator to be prudent when he translates. The translator must have common sense so that his translation will be logical and not violate what everybody knows. For example, there is a sentence in Rose, Rose, All the Way, that is, "(Margaret Thatcher) gave voice to Britain's reluctance about joining Europe", its Chinese translation is that “并且明确表示了英国不加入欧洲” which means Thatcher held that Britain was not part of Europe. However, everyone knows that Britain is a European country, and it is just common sense. If the translator just does some research or has paid a little attention to the world affair, he will know that here "Europe" refers to the Eurozone. The translator actually starts to translate without further thinking and thus fails to hold his responsibilities. In addition, each scholar has his own understanding of the translator's responsibilities. But all in all, he has to be a person who bears in mind that translation is not a casual job and who is willing to make endless efforts in the first place.

\section{References}

[1] Andrew Chesterman. Proposal for a Hieronymic oath [A]. Anthony. P. (ed.). The Return to Ethics, Special issue of The Translator [C]. Manchester: St. Jerome Publishing, 2001.

[2] Anthony Pym. (ed.). The Return to Ethics, Special issue of The Translator 7(2) [M]. Manchester: St. Jerome Publishing, 2001.

[3] J. C. Catford. A Linguistic Theory of Translation [M]. London: Oxford University Press, 1965.

[4] Miranda Steel. Oxford Intermediate Learner's English-Chinese Dictionary $[\mathrm{M}] .3^{\text {rd }}$ edition). The Commercial Press and Oxford University Press, 2009.

[5] Chen Dun. The Outline of the History of Foreign Literature [M]. Beijing: Beijing Normal University Press, 2007.

[6] Chen Zhijie, Yi Songming. Realizing a Translator's Responsibilities [J]. Journal of PLA University of Foreign Languages, (5): 77, 2011.

[7] Chi Changhai. A Textbook in Chinese Grammar and Rhetoric [M]. Zhejiang University, 2014.

[8] Hu Gengshen. An Eco-translatological Perspective on the Supersession of "Translator-centeredness" by "Translator's Responsibility” [J]. Chinese Translators Journal, (1), 2014.

[9] Liu Yunhong. Challenge of Translation and Responsibility of Criticism. [J]. Foreign Languages in China, (5): 88-93, 2014.

[10] Liu Yunhong. Identity, Choice, and Responsibility: An Interpretation of Anthony Pym's On Translator Ethics [J]. Chinese Translators Journal, (5), 2014.

[11] Lv Jun, Hou Xiangqun. An Introduction to Translatology [M]. Shanghai: Shanghai Foreign Language Education Press, 2012.

[12] Mu Lei, Zou Bin. How Translation Has Been Defined and Conceptualized in China: The Status Quo, the Existing Problems, and Some Reflections [J]. Chinese Translators Journal, (3), 2015. 
[13] Po Shi. The Translation of The Luncheon [J]. English Language Learning, (6), 2002.

[14] Ren Dongsheng. The Institutionalization of Translation and the Institutionalized Translation [J]. Chinese Translators Journal, (1), 2015.

[15] Song Xuezhi. What is a Classic of Literary Translation? [J]. Chinese Translators Journal, (1), 2015.

[16] Sun Zhili. The Translator's Responsibilities [J]. Chinese Translators Journal, (4): 7-10, 2007.
[17] Tan Weiguo. A New Textbook in Translation Between English and Chinese [M]. Shanghai: East China University of Science and Technology Press, 2011.

[18] William Somerset Maugham. A Selection Short Stories by W Somerset Maugham [M]. Beijing: Yilin Press, 2012.

[19] Xie Tianzhen. An Introduction to Contemporary Foreign Translation Theories $[\mathrm{M}]$. Tianjin: Nankai University Press, 2008. 